\title{
MAPEAMENTO DAS EMISSÕES DE GASES DE EFEITO ESTUFA EM UMA EMPRESA DO SETOR ENERGÉTICO
}

\author{
HARleson Bruno Oliveira ARRUdA ${ }^{1}$ \\ ${ }^{1}$ Instituto Federal de Educação, Ciência e Tecnologia do Ceará - IFCE \\ $<$ harlesonb@gmail.com>
}

DOI: 10.21439/conexoes.v12i3.1148

\begin{abstract}
Resumo. O aquecimento do planeta Terra pode causar diversos impactos negativos à humanidade. Os gases de efeito estufa (GEE) emitidos à atmosfera, principalmente após a Revolução Industrial, são os grandes causadores das mudanças climáticas. As empresas têm papel de destaque no aumento dos GEE, sendo tarefa destas desenvolver mecanismos que reduzam suas emissões. Para que haja a redução das emissões é necessário ter conhecimento das fontes de emissão e quanto estas emitem. O instrumento utilizado para a identificação e a medição dos gases estufa é o inventário. O objetivo desse estudo é identificar as fontes emissões de GEE, aplicando a ferramenta disponibilizada pelo Programa Brasileiro GHG Protocol, de uma empresa do setor de energético que atua no estado de Ceará. Para isso elaborou-se um estudo de caso da empresa. A metodologia partiu da coleta de dados sobre as fontes de geração de GEE da organização, por meio da solicitação em visitas e por e-mails encaminhados à Área de Meio Ambiente da empresa. Em seguida, as informações foram lançadas na ferramenta de cálculo do Programa Brasileiro GHG Protocol e feitas as análises. A fontes foram identificadas e ações de controle, monitoramento e reduções dos GEE foram propostas.
\end{abstract}

Palavras-chaves: Mudanças Climáticas. Sustentabilidade. Inventário de GEE.

\section{MAPPING OF GAS EMISSIONS GREENHOUSE IN A COMPANY'S ENERGY SECTOR}

\begin{abstract}
The warming of planet Earth can cause various negative impacts on humanity. The greenhouse gases (GHGs) emitted into the atmosphere, especially after the Industrial Revolution, are a major cause of climate change. Businesses have an important role in the increase of greenhouse gases, and these task to develop mechanisms that reduce their emissions. So there is the reduction of emissions is necessary to know the sources of emissions and how much they emit. The instrument used for the identification and measurement of greenhouse gases is the inventory. The aim of this study is to identify the sources of GHG emissions, using the tool provided by the Brazilian GHG Protocol Program, a company in the energy sector which operates in the state of Ceará. For it was elaborated a business case study. The methodology set out data collection on the sources of the organization's GHG generation, by requesting visits and emails sent to Medium Area business environment. Then the information was released in the calculation tool Brazilian GHG Protocol Program and made the analysis. The sources were identified and control measures, monitoring and reduction of greenhouse gases have been proposed.
\end{abstract}

Keywords: Climate Change. Sustainability. GEE inventory.

\section{INTRODUÇÃO}

O desafio climático tornou-se o grande tema discutido por nações que buscam o denominador comum entre o crescimento econômico e o desenvolvimento sus- tentável. Os gases de efeito estufa vêm causando grandes alterações climáticas que atingem o globo e coloca em risco o futuro da humanidade. Os combustíveis fosseis, principais fontes de emissão de gases de efeito es- 
tufa, foram a energia motriz das industrias e, mais tarde, dos automóveis (CALVACANTI, 2009). As mudanças climáticas podem ser definidas como:

\begin{abstract}
Mudança climática é o nome que se dá a um conjunto de alterações nas condições do clima da Terra em consequência do acúmulo de seis gases - como o dióxido de carbono (CO2) e o metano (CH4) - na atmosfera, emitidos em quantidade excessiva há pelo menos 150 anos, desde a Revolução Industrial, através da queima de combustíveis fósseis, como o petróleo e o carvão, e do uso inadequado da terra com a conversão das florestas e da vegetação natural em pastagens, plantações, áreas urbanas ou degradadas. (RICARDO; CAMPANILI 2005, p. 295).
\end{abstract}

O conhecimento das causas e consequências das mudanças climáticas fez com que organizações empresariais, as instituições civis e governos buscassem a redução da poluição do ambiente causada pelo lançamento dos Gases de Efeito Estufa (greenhouse gases GEE). Vários são os mecanismos de medição dos chamados GEE adotados. A ferramenta disponível para a medição dos GEE indicada pelo Painel Intergovernamental Sobre Mudanças Climáticas (IPCC, sigla em inglês) é o inventário de emissões de GEE (IPCC, 2007).

Segundo informações do IPCC (2007) o setor energético mundial colabora com $25 \%$ total com a emissão de GEE na atmosfera global, para tanto, empresas pertencentes a este mercado buscam criar ferramentas que reduzam suas emissões afim de aproveitar as oportunidades que surgem com estabelecimento de restrições de emissões. O inventario é primeiro passo a ser dado pelas empresas que buscam gerenciar suas emissões de GEE.

As organizações utilizam os inventários baseados nas normas de contabilização do IPCC e da Organização Internacional para a Padronização (ISO, sigla em inglês). No Brasil e no mundo, existem diversos mecanismos de contabilização e divulgação dos relatórios de emissões, que visam a padronização dos instrumentos para o melhor entendimento das fontes de emissão afim de mitigar seus efeitos, dentre eles destaca-se o Greenhouse Gas Protocol (WRI, 2004).

Observando-se as informações supracitadas tem-se a dimensão da importância de as empresas elaborarem seus inventários de GEE. São poucas as organizações que usam esse instrumento de gestão ambiental. Poucos também são, no Brasil, os estudos sobre as ferramentas utilizadas para elaboração dos inventários. Devido ao hiato entre a importância desse instrumento e a falta de aplicação pelas empresas e instituições acadêmicas é que se justifica o estudo.
O presente estudo tem por objetivo geral identificar o perfil de emissões, fontes e volumes, de uma empresa de distribuição de energia no Ceará, aplicando a ferramenta de contabilização de GEE disponibilizada pelo Programa Brasileiro GHG Protocol. Como objetivos específicos propor medidas de controle e monitoramento desses gases afim de reduzi-los.

\section{REFERENCIAL TEÓRICO}

\subsection{EMISSÕES ATMOSFÉRICAS E MUDANÇAS CLIMÁTICAS}

A Terra é envolvida por diversas camadas de gases, a chamada atmosfera. Em uma dessas camadas, a estratosfera, ocorre o efeito estufa. Esse fenômeno acontece quando a Terra absorve a energia (calor) emitida pelo sol e em seguida a irradia de volta, contudo parte desse calor é mantida na atmosfera devido à presença de alguns gases, os gases estufa, que impedem que a radiação solar retorne ao espaço (BRAGA et al, 2005). O efeito estufa é um evento necessário à sobrevivência dos seres humanos, pois, sem ele o planeta atingiria temperaturas extremamente baixas. May, Lustosa e Vinha (2003) informam que esse efeito acontece há milhares de anos, tratando-se de efeito natural que propicia as condições ideais para a sobrevivência.

O dióxido de carbono ( $\mathrm{CO} 2)$ é gás de efeito estufa mais importante, pois a sua concentração na atmosfera desde a era pré-industrial, 280 ppm (parte por milhão), até meados dos 2000, 379 ppm, cresceu de forma assustadora. Esse gás é emitido, principalmente, pela queima de combustíveis fosseis, ação de origem humana. O dióxido de carbono é considerado o principal responsável pelo aumento da temperatura da Terra (IPCC, 2007).

Segundo Stern (2007), evidências científicas indicam que o clima da Terra está mudando rapidamente, principalmente como resultado do aumento de gases de efeito estufa causadas pelas atividades humanas, principalmente após a revolução industrial. O Painel Intergovernamental sobre Mudanças Climáticas Globais (IPCC, 2007) tem certeza de $90 \%$ que o aquecimento global, nos moldes atuais, tem sido intensificado pelas atividades humanas. Entre os maiores emissores estão as empresas do setor de energia elétrica que no ano de 2004 emitiu cerca de $26 \%$ do total de emissões de GEE mundial. A queima de carvão, petróleo e gás natural para geração de energia são as principais causas do aumento do dióxido de carbono na atmosfera.

O problema da mudança climática tem conduzido uma lenta, porém real, mudança da matriz energética mundial. O Brasil apresenta baixos índices de emissão de GEE advindos do setor energético se comparado com outros países do globo. Um consumo per capita 
de energia elétrica baixo somado a alta participação de fontes renováveis, principalmente a hidroelétrica, contribuem para esse panorama nacional (GVCES, 2010).

A matriz energética nacional é composta por diversas fontes, como a biomassa, a eólica, a fóssil, a hídrica, a nuclear, a solar e através da importação de energia de países vizinhos. Dentre estas destaca-se as hidroelétricas que corresponde a $61,22 \%$ da geração de energia do Brasil no ano de 2014. Esta fonte de energia elétrica é altamente vulnerável às mudanças no clima e a sazonalidade na disponibilidade hídrica. Quando a demanda por energia ultrapassa a capacidade de atendimento das hidroelétricas, as geradoras térmicas são acionadas o que aumenta a contribuição do setor para as emissões de GEE. Atualmente, as geradoras a base de combustível fóssil são responsáveis por cerca de $17,17 \%$ da energia nacional e quando estas são acionadas, em caso de indisponibilidade hídrica para geração de energia, as emissões de GEE brasileiras aumentam (ANEEL, 2016 GVCES, 2010, SCHAEFFER et al., 2008).

Os impactos produzidos pelas mudanças climáticas trazem prejuízos à humanidade em diversos pontos; com efeitos sobre o meio ambiente, a economia e a sociedade. As projeções revelam grandes mudanças nas condições climáticas globais com mudanças em regimes pluviais e o aumento de situações catastróficas: secas mais intensas, cheias irregulares, tufões, furacões, aumento do nível do mar e a perda de diversas espécies. Há evidencias de perdas de massa de gelo nos polos acarretando o aumento do nível dos oceanos e a perdas de terras que se situam à nível do mar, países baixos (BARBIERI, 2007; IPCC, 2014).

O IPCC (2014) informa sobre as consequências do aumento na temperatura e preocupa-se, especialmente, com a irregularidade hídrica visto que esse recurso é a base para a sobrevivência da humanidade, desde o consumo humano individual ao seu uso em diversas atividades econômicas. Dentre as atividades diretamente afetadas pela mudança no ciclo da água estão: a agricultura, o transporte e a geração de energia.

O acesso das organizações empresariais à água será dificultado o que levará ao aumento dos custos para encontrar e tratar o recurso. As inundações terão papel fundamental na perda de capital das empresas e da sociedade, com grandes prejuízos para as empresas seguradoras. Os governos gastarão mais dinheiro na adequação das cidades a nova dinâmica do clima. Já a escassez acirrará os conflitos pela posse da água (IPCC 2014; STERN, 2007).

Stern (2007) informa em seu estudo que mesmo as projeções mais moderadas anunciam impactos sérios na produção, na vida humana e no ambiente mundial. Por isso, as grandes corporações têm que incorporar a mudança climática em suas estratégias de negócio e os governos propor soluções para mitigar os impactos.

\subsection{AS DISCUSSÕES EM BUSCA DA SOLUÇÃO PARA AS MUDANÇAS CLIMÁTICAS}

O primeiro evento mundial a discutir as mudanças climáticas aconteceu na cidade de Toronto, no Canadá, em 1988. A chamada de Conferência Mundial sobre Mudanças Atmosféricas (The Changing Atmosfere: Implications for Global Security). A partir desse momento, percebeu-se a necessidade de criar uma agenda mundial para o tema. No mesmo ano foi criado o Painel Intergovernamental sobre Mudanças Climáticas. Este painel foi estabelecido pela Organização Meteorológica Mundial (OMM) e pelo Programas das Nações Unidas para o Meio Ambiente (PNUMA), para balizar cientificamente as questões sociais, técnicas e ambientais disponíveis sobre a mudança do clima, para que os "tomadores de decisão" tenham disponíveis informações seguras (MAY; LUSTOSA; VINHA, 2003, MCTI, 2016).

\footnotetext{
A necessidade de formação desse painel baseavase no reconhecimento da enorme complexidade do sistema climático, do elevado risco trazido pela mudança climática e da necessidade de uma fonte objetiva de informação técnica, cientifica e sócioeconômica sobre as causas e impactos da mudança climática, assim como as possíveis medidas de resposta, incluindo a comparação dos custos e benefícios da ação contra os da inação (MAY; LUSTOSA; VINHA, 2003, p. 224).
}

Fazem parte do IPCC cientistas do mundo todo que contribuem como autores, colaboradores e revisores. As publicações do painel prezam pela simplicidade na abordagem das questões para o melhor entendimento por parte das pessoas. A transparência é outra característica do relatório para que este não dê margem as especulações. A composição dos relatórios engloba diversas áreas de conhecimento que influenciam no entendimento da mudança climática como: ciência física da mudança climática, impactos, adaptação, vulnerabilidades e mitigação (MCTI, 2016).

Em 1992 aconteceu, no Rio de Janeiro, Conferência das Nações Unidas sobre Meio Ambiente e Desenvolvimento (RIO-92). A Convenção-Quadro das Nações Unidas sobre Mudança do Clima (UNFCCC, sigla em inglês) é um dos documentos lançados naquela conferência. No tratado os países signatários reconhecem a mudanças do clima como um dano que atinge a humanidade e que decisões globais devem ser tomadas, afim de elaborar uma estratégia mundial para defesa do sistema climático global (MCTI, 2016; FIESP, 2011). 
Para May, Lustosa e Vinha (2003) a importância do UNFCCC vem da possibilidade da tomada de decisão coletiva das partes signatárias que negociam ações futuras. A busca do conhecimento técnico sobre os impactos das mudanças do clima e a proposição de estratégias que buscam proteger o sistema climático para gerações presentes e futuras.

O órgão supremo da Convenção-Quadro é a Conferência das Partes (COP). O órgão reúne-se periodicamente para deliberar sobre questões envolvidas na mudança climática. As maiores deliberações a respeito de conceitos e tecnologias de integração meio ambiente e desenvolvimento, pressupostos da sustentabilidade, derivam de medidas tomadas pelas Conferencias das Partes (BARBIERI, 2007).

A conferencia é realizada anualmente desde o ano de 1995, entre os vários encontros que aconteceram das COP a Conferência das Partes 3 (COP-3) realizada em Quioto é considerado por Barbieri (2007) o grande avanço em termos de gestão ambiental da mudança do clima. Em 1997, na (COP-3), surge o documento intitulado protocolo de Quioto.

A UNFCCC (1998) define o protocolo de Quioto como sendo um acordo vinculado à Convenção-Quadro das Nações Unidas sobre a Mudança do Clima que estabelece que as Partes do Anexo I, países desenvolvidos, reduzam, individual ou conjuntamente, as emissões totais de gases de efeito estufa originários de fonte antropogênica em 5\% dos níveis registrados em 1990, no período de 1998 a 2012. Contudo, o protocolo deveria ser ratificado por 55 nações-Partes que representassem cerca de 55\% das emissões de gases de efeito estufa. Isto ocorreu no ano de 2005, quando Rússia ratifica o protocolo. Nesta época 141 países eram Partes e representavam $60 \%$ das emissões globais.

O Protocolo de Quioto regula quatro gases e duas famílias de gases de efeito estufa: 1) Dióxido de carbono (CO2), 2) Metano (CH4), 3) Óxido nitroso (N2O), 4) Hexafluoreto de enxofre (SF6), 5) Hidrofluorcarbonos (HFCs), 6) Perfluorcarbonos (PFCs). Para May, Lustosa e Vinha (2003) estes gases foram escolhidos por serem os mais representativos e dentre eles o $\mathrm{CO} 2$ assume um papel de destaque. Outras substâncias que são GEE, clorofluorcarbonos (CFCs) e hidroclorofluocarbonos (HCFCs), e que não são controladas pelo Protocolo de Quioto estão comtempladas no Protocolo de Montreal, devido sua capacidade de depleção da camada de ozônio (FIESP, 2011). Existem mecanismos que visam a flexibilização do Protocolo de Quioto. Tratam-se de instrumentos facilitadores para que os países desenvolvidos, chamados de países do Anexo I, atinjam suas metas de redução de gases. Abaixo $\mathrm{FI}-$
ESP (2011) define esses instrumentos.

- Comércio de emissões - países do Anexo I que tenham atingido suas metas de redução podem transferir o excesso de redução para outros países do mesmo anexo.

- Implementação conjunta - países do Anexo I implantam projetos de redução de GEE em países que tenham metas de redução.

- Mecanismo de Desenvolvimento Limpo (MDL) - mecanismo que permite aos países do Anexo I adquirirem reduções certificadas de países Não Anexo I, nações em desenvolvimento. As regras para esse mecanismo são definidas por cada país signatário do protocolo, conforme critério próprio.

O Protocolo de Quioto em seus artigos trata, ainda, da elaboração de inventários de gases de efeito estufa. Os países Partes da Convenção-Quadro têm o compromisso de elaborar, atualizar periodicamente e publicar seus relatórios de inventários nacionais de GEE. Os países do Anexo I devem elaborar inventários anuais. Os países Não Anexo I devem elaborar inventários periodicamente como parte de suas comunicações nacionais à Convenção (UNFCCC. 1998).

\subsection{PROGRAMA BRASILEIRO GHG PROTOCOL}

Lückemeyer (2010) informa que o número de empresas que medem e elaboram seus inventários ainda é pequeno. Os inventários realizados por empresas são de caráter voluntário e podem significar um primeiro passo na identificação de oportunidades de negócios. Para Brasil, Junior e Junior (2008) o inventário de emissões de GEE, feito de forma correta e de acordo com as normas internacionais de contabilização desses gases, é instrumento de otimização da gestão operacional de qualquer empresa, pois favorece a revisão de procedimentos de transformação de insumos em produtos, melhorando a eficiência dessa transformação e diminuindo os custos.

Existem vários benefícios de se realizar um inventário de GEE segundo $\mathrm{FGV}(2009)$ dentre eles: oportunidade da redução de custos devido a melhoria de processos gerenciais, redução ou otimização no uso de energia; criação de benchmark e oportunidades para melhorar a competitividade, tendo por base a comparação do ciclo de vida de produtos similares; participação no mercado de emissões de GEE, através de projetos geradores de crédito de carbono; segurança aos acionistas, diminuindo os riscos/incertezas; replicabilidade na cadeia de valor; alcance de metas de responsabilidade 
socioambiental; redução de passivos e redução nos riscos devido maior restrição de políticas públicas; garantir oportunidades no mercado internacional, garantias de boa gestão em sustentabilidade.

Machado (2013) informam que existem diversas ferramentas para o cálculo de emissões de gases de efeito estufa e dentre elas a mais utilizada é a do programa GHG protocol. A sua utilização em grande escala está associada a compatibilização com as normas da ISO, especificamente a ISO 14.064, e as metodologias de quantificação do IPCC.

Essa metodologia foi desenvolvida pelo World Resources Institute - WRI em parceria com o World Business Council for Sustainable Development - WBSCD e estabelece o padrão global para a forma de medir, gerenciar e relatar as emissões de gases de efeito estufa (GHG, 2016, WRI, 2004).

No Brasil, o Programa GHG Protocol foi lançado 12 de maio de 2008, em Brasília, para promover a gestão de gases de efeito estufa voluntária, através da construção de capacidade técnica e institucional para a contabilização de GEE e relatórios no nível organizacional. É uma parceria do Ministério do Meio Ambiente (MMA), o Conselho Empresarial Brasileiro para o Desenvolvimento Sustentável (CEBDS), a Fundação Getúlio Vargas (FGV) e o Conselho Empresarial Mundial para o Desenvolvimento Sustentável (WBSCD, sigla em inglês) (FGV, 2009).

As empresas que se tornam membros do Programa Brasileiro GHG Protocol têm a oportunidade de participar das oficinas de capacitação no método GHG Protocol e dispõem de atendimento técnico remoto e/ou presencial para solucionar questões sobre seus inventários, além de contribuírem com a formatação dos novos métodos e ferramentas de cálculo. Os seus inventários são publicados no registro público de emissões de GEE e no próprio site do Programa Brasileiro GHG Protocol (GHG, 2016).

Para a contabilização e elaboração do relatório de emissões de GEE o Programa GHG Protocol estabelece cinco princípios, Tabela 1 .

Os gases inventariados são os regulados pelo Protocolo de Quioto. O programa defini o passo a passo, a ser seguido pelas empresas para a elaboração do inventário de GEE (FGV, 2009).

Passo 1: Definir os limites organizacionais

As empresas definem seus limites organizacionais ao escolher uma abordagem para o levantamento, registro, consolidação e comunicação das suas emissões (WRI, 2004). O Programa Brasileiro GHG Protocol utiliza-se de duas abordagens para o estabelecimento dos limites organizacionais: i) Participação societária: as empresas que se utilizam da participação societária devem incluir em seu inventário as fontes as quais tem participação societária na operação, integralmente ou parcialmente. ii) Controle operacional: as empresas devem incluir $100 \%$ das fontes que estão sobre seu controle e nenhuma fonte que não está totalmente sobre seu controle (GHG, 2016).

Passo 2: Definir os limites operacionais

Determina-se pela identificação das emissões provenientes das atividades operacionais da empresa, podem ser diretas ou indiretas. As emissões diretas são aquelas que advém de atividades que são exercidas ou controladas diretamente pela empresa. As indiretas são as emissões advindas das atividades de suporte à empresa, realizadas por fornecedores.

O Protocolo GHG Brasil define também o conceito de "escopo", de forma a auxiliar as empresas a estabelecer e facilitar a identificação do que deve ser contabilizado. Há três escopos: escopo 1 - emissões de GEE diretas - emissões de GEE da própria empresa, que pertencem ou são controladas por ela; escopo 2 - emissões de GEE indiretas - emissões líquidas a partir da compra de energia e escopo 3 - outras emissões de GEE indiretas - Todas as outras fontes de emissão possivelmente atribuíveis à atividade da empresa, mas quem não pertencem ou são controladas por ela (WRI, 2004).

Passo 3: Selecionar a metodologia de cálculo e fatores de emissão

O Programa Brasileiro GHG Protocol desenvolve e disponibiliza em seu site, anualmente, ferramentas de medição que levam em consideração as peculiaridades dos setores da economia brasileira. As ferramentas desenvolvidas buscam assegurar qualidade aos inventários e são divididas em duas categorias, intersetoriais ou especificas de setores (FGV, 2009).

Passo 4: Coletar dados

A coleta de informações sobre possíveis fontes de geração de emissões deve se realizar conforme as especificidades da operação da empresa e das próprias fontes. Deve-se respeitar o escopo definido no primeiro passo (FGV, 2009).

Passo 5: Calcular emissões

As organizações podem utilizar as ferramentas disponibilizadas pelo Programa para garantir maior precisão. As ferramentas disponham de explicações passo a passo, sendo o seu uso opcional. As ferramentas de cálculo de emissões são disponibilizadas para as empresas que buscam realizar seus inventários, sejam elas participantes ou não do programa. A organização pode desenvolver e utilizar métodos próprios de contabilização de GEE, contudo estes devem ser mais precisos que as ferramentas disponibilizadas e em conformidade com o 
Tabela 1: Princípios para a contabilização e elaboração do relatório.

\begin{tabular}{|c|c|}
\hline Princípio & Descrição \\
\hline Relevância & $\begin{array}{l}\text { O inventário deve refletir com exatidão os limites da empresa. A informação deve servir de } \\
\text { apoio à decisão para o público interno e externo à organização. }\end{array}$ \\
\hline Integralidade & $\begin{array}{l}\text { Registrar e comunicar todas as fontes de emissão dentro do limite do inventário selecionado } \\
\text { e justificar exclusões, caso existam. }\end{array}$ \\
\hline Consistência & $\begin{array}{c}\text { Utilização de dados, métodos, critérios e premissas que permitam comparações } \\
\text { válidas e significativas. }\end{array}$ \\
\hline Transparência & $\begin{array}{l}\text { Fornecer informações claras e suficientes para que revisores externos possam avaliar a } \\
\text { credibilidade e confiabilidade dos dados apresentados. }\end{array}$ \\
\hline Exatidão & Reduzir as incertezas tanto quanto possível. \\
\hline
\end{tabular}
Fonte: (GHG, 2016).

GHG Protocol Corporate Standart (GHG, 2016).

Passo 6: Elaborar o relatório de emissões de GEE

O relatório deve-se ser elaborado conforme especificação da delimitação dos limites da organização, obedecendo às diretrizes do Programa Brasileiro GHG Protocol que determina que um relatório inventario deve conter: a descrição das fontes de emissão e dados das emissões dos seis GEE separadamente; a explicação de inclusões ou exclusões de fontes; o período de reporte e a metodologia usada para medir as emissões; a definição do ano base para comparação temporal; o progresso em relação as metas estabelecidas anteriormente; a discursão das incertezas dos dados de emissões comunicados e a discursão de mudanças que tenham impactado nos dados comunicados (FGV, 2009).

\section{METODOLOGIA}

O estudo foi realizado em uma empresa de distribuição de energia elétrica que opera em todo o estado do Ceará. A pesquisa abrangeu todas as unidades operacionais e os centros de serviços da empresa estudada. O referencial teórico foi formulado por meio de pesquisa bibliográfica em diversas fontes como livros, dissertações, teses e sites que tratam do assunto. Na identificação dos gases de efeito estufa associados à operação da empresa e suas respectivas fontes, utilizou-se as diretrizes do Programa Brasileiro GHG Protocol. O cálculo foi realizado por meio da "Ferramenta_GHG_Protocol_v2016.2" , disponibilizado pelo programa em seu site (<http://www. ghgprotocolbrasil.com.br/ferramenta-de-calculo $>$ ).

A ferramenta caracteriza-se por uma planilha que contém diversas abas, cada uma corresponde a um tipo de fonte de emissão. A planilha de cálculo é composta por fatores de emissão baseados em publicações de organismos reconhecidos internacionalmente, a atualização dos fatores de emissão acontece anualmente conforme uma nova ferramenta é lançada. Na parte inicial da ferramenta insere-se as informações organizacionais como o nome da empresa, endereço, segmento e data, esta é importante pois alguns fatores de emissão mudam anualmente, como o de emissões por consumo de energia que depende da disponibilidade hídrica para a geração de energia e o acionamento das térmicas.

As informações sobre as emissões são inseridas nas abas seguintes que estão divididas em três escopos que se subdividem em categorias. Escopo 1: combustão estacionária (ex. geradores); combustão móvel (ex. frota de veículos da empresa); emissões fugitivas (ex. gases utilizados em condicionadores de ar e extintores); processos industriais (ex. produção de alumínio); atividades agrícolas e mudanças no uso do solo (ex. produção de grãos); Resíduos sólidos (ex. resíduos orgânicos que vão para aterros) e efluentes (ex. esgoto). Escopo 2: compra de energia elétrica (ex. consumo anual de energia utilizada na produção e/ou atividades administrativas) e compra de energia térmica (ex. vapor para utilização em caldeiras). Escopo 3: atividades realizadas por fornecedores ou prestadores de serviços onde destacam-se as emissões de "Viagens a negócios", o consumo de combustíveis e gerenciamento de resíduos de fornecedores.

As últimas abas da ferramenta são informações referentes ao resumo do total de gases emitidos por escopo e categoria. As abas restantes tratam apenas de informações sobre os fatores de emissão e de conversão utilizados. A ferramenta utiliza como unidade de medida o $\mathrm{CO} 2$ equivalente (CO2e), padrão internacional de medida dos GEE. O dióxido de carbono equivalente resulta da multiplicação das toneladas emitidas do GEE pelo seu potencial de aquecimento global.

A coleta das informações foi realizada diretamente na empresa por meio de visitas e correios eletrônicos enviados à área de meio ambiente da empresa que cedeu informações sobre as fontes de gases estufa dos anos 2011 a 2015. Planilhas e e-mails foram dispo- 
nibilizados com informações sobre diversas possíveis fontes geradoras de GEE, conforme sua utilização na ferramenta. As informações são provenientes de diversas áreas da organização como: transportes, utilidades, manutenção, regulação, e a própria área de meio ambiente.

As informações sobre o consumo de combustíveis dos veículos próprios e contratados foram disponibilizadas em planilhas pela área de transportes. As planilhas informam o tipo de frota, própria ou contratada; o tipo de combustível; a quantidade de litros consumido e o total de quilômetros percorridos pela frota durante o ano, mês a mês. $\mathrm{O}$ uso de taxi também foi informado pela área de transportes através de uma planilha que contém a quilometragem percorrida pelos taxis utilizados por funcionários à serviço da empresa. As viagens aéreas foram informadas em planilha com a distância percorrida pelos voos nos quais haviam funcionários da empresa.

A área de utilidades informou, por e-mail, a quantidade de combustível, em litros, utilizado em geradores de energia elétrica e a quantidade de gases, em quilos, provenientes de equipamentos de refrigeração e ar condicionados (RAC).

Emissões fugitivas de SF6 foram informadas pela área de manutenção. A área de meio ambiente, trimestralmente, solicita a área de manutenção informações sobre a fuga deste gás, em quilos, e preenche uma planilha própria para controle.

As quantidades de resíduos encaminhados ao aterro sanitário foram informadas pela área de meio ambiente que faz o controle mensal, as informações são enviadas pelos diversos centros de serviço da empresa. A energia consumida foi informada pela área de regulação, por meio de planilha do consumo mensal de todos os prédios utilizados nas atividades da empresa.

Após a coleta, as informações foram lançadas na planilha de cálculo e, em seguida, feitas as análises e proposições.

\section{RESULTADOS E DISCUSSÕES}

Dispondo das informações sobre as fontes de emissões de GEE dos anos de 2011 a 2015, obteve-se o gráfico da Figura 1 com as quantidades de emissões brutas para a série temporal.

Nota-se que nos primeiros anos analisados, 2011 a 2013, houve pouca variação de um ano para o outro, mas ao verificarmos os anos seguintes, 2014 e 2015, houve um aumento considerável das emissões. O aumento decorre de dois fatores principais identificados, o primeiro é aumento das emissões por utilização de energia elétrica devido ao acionamento das termelétri-

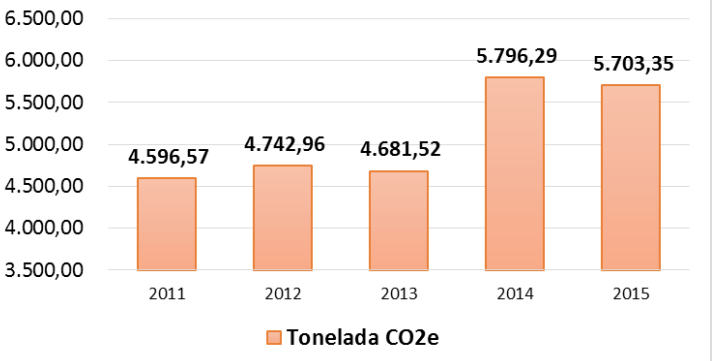

Figura 1: Emissões de GEE na empresa nos de 2011 a 2015. Fonte: elaborado pelo autor (2016).

cas e o segundo refere-se a uma melhor captação e tratamento das informações sobre as fontes de emissões de gases estufa. A análise desses anos, de acordo fontes de emissões, pode ser realizado através do gráfico da Figura2

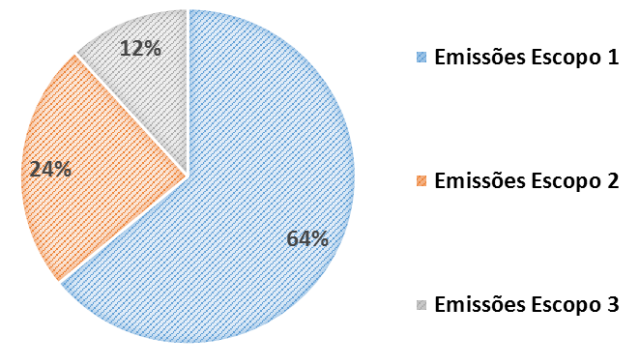

Figura 2: Participação das fontes de emissões por escopo. Fonte: elaborado pelo autor (2016).

As emissões diretas de escopo 1 são responsáveis pela maior parte de emissões GEE da empresa, 64\%, sendo maior do que a soma dos outros dois escopos restantes, os escopos 2 e 3 juntos somam $36 \%$, respectivamente $24 \%$ e $12 \%$, das emissões brutas nos anos analisados. Com isso torna-se imprescindível o conhecimento das fontes de emissões, principalmente as do escopo 1 .

\subsection{Emissões de Escopo 1}

Estas emissões são de fontes que estão totalmente sob controle da empresa. A Tabela 2 traz um resumo das fontes de escopo 1 com quantidades de emissões por fontes para os anos de 2011 a 2015.

A maior a fonte de emissão de GEE do escopo 1 é o transporte de funcionários à serviço da empresa, realizado por veículos da frota própria e contratada. Essas emissões alcançam 58,50\% das emissões total do escopo. Dos veículos utilizados os que mais emitem são 
MAPEAMENTO DAS EMISSÕES DE GASES DE EFEITO ESTUFA EM UMA EMPRESA DO SETOR ENERGÉTICO

Tabela 2: Participação das fontes de emissões por escopo.

\begin{tabular}{|c|c|c|c|c|c|}
\hline \multirow[b]{2}{*}{ Fonte } & \multicolumn{5}{|c|}{ Emissōes de Escopo 1} \\
\hline & 2011 & 2012 & 2013 & 2014 & 2015 \\
\hline Geradores & 2,99 & 8,16 & 23,56 & 13,78 & 0,69 \\
\hline Transporte de funcionarios & $1.816,88$ & $1.873,89$ & $1.967,30$ & $2.093,2$ & $1.805,10$ \\
\hline Condicionador de ar e SF6 & $1.652,66$ & 1.376 .58 & 594,41 & 666.2 & $1.552,49$ \\
\hline $\begin{array}{l}\text { Resíduos orgánicos } \\
\text { aterrados }\end{array}$ & 143,45 & 119,69 & 187,65 & 206,8 & 229,63 \\
\hline Total de Emissōes Escopo 1 & $3.615,98$ & $3.378,32$ & $2.772,92$ & $2.979,97$ & $3.587,91$ \\
\hline
\end{tabular}

Fonte: elaborado pelo autor (2016).

os movidos a óleo diesel, cerca de $74,88 \%$ do total emitido pelos carros.

A segunda maior fonte são as de emissões fugitivas de gases utilizados nos condicionadores de ar e o SF6, utilizado como isolante elétrico nos transformadores. Este último colabora com $46 \%$ de todas emissões desse tipo e tem um alto poder de aquecimento, por isso pequenas quantidades desse gás podem causar grandes estragos à atmosfera. Os outros gases são o R-407C e $\mathrm{R}-404 \mathrm{~A}$, gases refrigerantes, e o CO2 utilizado em extintores de incêndio.

As outras fontes são os resíduos orgânicos aterrados e o combustível utilizado nos geradores de energia, juntos eles contribuem com um pouco mais de $5 \%$ das emissões do escopo. As emissões de resíduos aterrados tendem a aumentar, pois calcula-se as emissões acumuladas da disposição de resíduos no aterro sanitário, para isso a ferramenta estabelece um horizonte de emissões para 30 anos, tempo necessário à decomposição da matéria orgânica em aterros sanitários.

\subsection{Emissões de Escopo 2}

A Tabela 3 expõe as emissões do consumo de energia elétrica na empresa, segundo maior contribuinte em emissões (24\%). As emissões desse tipo são dependentes do consumo interno de energia elétrica e da composição nacional anual de suas fontes de geração elétrica.

Tabela 3: Fontes de GEE de Escopo 2, em CO2 equivalente (tCO2e)

\begin{tabular}{|c|c|c|c|c|c|}
\hline \multicolumn{6}{|c|}{ Emissōes de Escopo 2} \\
\hline Fonte & & & & & \\
\hline & 2011 & 2012 & 2013 & 2014 & 2015 \\
\hline $\begin{array}{l}\text { Eletricidade } \\
\text { consumida nas } \\
\text { unidades em }\end{array}$ & 412,93 & $\mathbf{9 6 5 , 3 8}$ & $1.294,39$ & $1.992,6$ & $1.516,2$ \\
\hline
\end{tabular}

Fonte: elaborado pelo autor (2016).

Nos últimos anos o país tem passado por crises hídricas que afetaram a produção de eletricidade por meio hídricos obrigando o acionamento das térmicas e por consequência o aumento das emissões de gases de efeito estufa.

\subsection{Emissões de Escopo 3}

As emissões do escopo 3, Tabela 4 , são as que menos contribuem no montante total. As viagens aéreas constituem quase a totalidade deste escopo, ficando com $93,38 \%$. As viagens de táxi ficam com 5,69\% e o transporte de resíduos por terceiros fica com menos de $1 \%$ das emissões.

Tabela 4: Fontes de GEE de Escopo 3, em CO2 equivalente (tCO2e).

\begin{tabular}{c|r|r|r|r|r}
\hline \multirow{2}{*}{ Fonte } & \multicolumn{7}{c}{ Total de Emissöes Escopo 3 } \\
\cline { 2 - 6 } & $\mathbf{2 0 1 1}$ & \multicolumn{1}{c}{$\mathbf{2 0 1 2}$} & \multicolumn{1}{c}{$\mathbf{2 0 1 3}$} & \multicolumn{1}{c}{$\mathbf{2 0 1 4}$} & \multicolumn{1}{c}{$\mathbf{2 0 1 5}$} \\
\hline $\begin{array}{c}\text { Viagens aéreas } \\
\text { (funcionários) }\end{array}$ & 538,90 & 384,10 & 541,42 & 779,74 & 561,04 \\
\hline Táxi & 17,23 & 12,50 & 70,67 & 37,81 & 32,61 \\
\hline Transporte de residuos & 11,53 & 2,65 & 2,13 & 6,14 & 5,61 \\
\hline $\begin{array}{c}\text { Total de Emissóes } \\
\text { Escopo 3 }\end{array}$ & $\mathbf{5 6 7 , 7}$ & $\mathbf{3 9 9 , 3}$ & $\mathbf{6 1 4 , 2}$ & $\mathbf{8 2 3 , 7}$ & $\mathbf{5 9 9 , 3}$ \\
\hline
\end{tabular}

Fonte: elaborado pelo autor (2016).

A elaboração e aprovação de legislações sobre as mudanças climáticas, em âmbito nacional e estadual, é iniciada com a promulgação da Lei Federal 12.187, de 29 de dezembro de 2009, que é a Política Sobre a Mudança do Clima (PNMC). Essa lei é regulamentada pelo Decreto $\mathrm{N}^{\mathrm{O}} 7.390 / 2010$ que estabelece ao poder público a incumbência de desenvolver planos setoriais de mitigação e adaptação aos impactos das mudanças climáticas, incluindo-se o setor de geração e distribuição de energia elétrica, tomando como base os inventários de GEE do setor. Contudo, não há na legislação citada o estabelecimento de padrões de emissões e nem de metas objetivas, tratando-se de instrumento institucional de pouca aplicação prática (BRASIL, 2009; BRASIL, 2010).

Em Ceará (2016) observa-se a Lei No 16.146/2016 que institui a Política Estadual Sobre Mudanças Climáticas (PEMC) onde se estabelecem normas gerais tais quais as observadas na PNMC. Como na norma federal, não há na PEMC o estabelecimento de parâmetros sobre as emissões de gases estufa, nem tampouco o direcionamento de medidas que visam a mitigação dos seus efeitos negativos. Devido a estas ausências, a proposição de soluções que visam o controle dos GEE, propostas nesse artigo, foram elaboradas a partir dos resultados encontrados nos inventários produzidos e da busca de práticas menos poluentes e economicamente viáveis.

\subsection{Medidas de Controle dos GEE}

As medidas de controle devem levar em consideração a contribuição da fonte e a possibilidade de redução destas. Para Hoffman (2006) a redução de emissões de GEE das quais a empresa tenha o controle do aspecto gerador, escopo 1 , tendem a ser as mais comuns. $\mathrm{O}$ con- 
trole operacional possibilita a redução de emissões significativas de gases estufa a curto prazo e baixo custo.

No Escopo 1, as emissões dos veículos que transportam os funcionários podem ser reduzidas ao se adotar automóveis mais econômicos e que utilizam combustíveis limpos. Também há possiblidade do melhoramento das rotas utilizadas pelos motoristas, existem no mercado equipamentos e/ou aplicativos que informam trajetos mais curtos e menos congestionados de carros, reduzindo o consumo de combustíveis. Outra medida seria a utilização de vídeo e/ou fonoconferência, quando se tratar de grandes distancias e for possível a utilização dessas tecnologias.

As emissões de gás SF6 podem ser reduzidas no momento da manutenção dos transformadores, a ação a ser tomada é simplesmente não deixar que o gás escape no momento da manutenção e acondiciona-lo para a realização de reciclagem. Os gases refrigeradores devem ser substituídos por outros menos poluentes.

Grande parte das emissões de GEE têm origem no consumo de energia elétrica. Essa constatação promoveu a busca de eficiência energética em corporações que objetivam uma economia de baixo carbono. A eficiência energética promove, além da diminuição de gases, uma economia financeira ocasionada pela redução da compra de energia (HOFFMAN, 2006).

Para a redução das emissões pelo consumo de energia elétrica, de Escopo 2, deve-se promover campanhas de sensibilização quanto ao uso eficiente de eletricidade. O prédio da administração central da empresa já é dotado de sensores de movimentos em áreas de convívio comum e ao final do expediente normal de trabalho a central de ar é totalmente desligada, essas medidas devem se estender aos outros prédios da empresa.

O escopo 3 são as emissões das quais a empresa não tem controle das operações que geram os GEE. Contudo algumas medidas podem ser tomadas para a redução destes. A principal fonte são as viagens aéreas que podem ser diminuídas quando houver a possibilidade da utilização fono e/ou videoconferências. Os táxis são usados em ocasiões emergenciais, isso faz que a gestão dos gases emitidos por essa fonte seja de difícil controle.

Em nível institucional algumas medidas podem ser tomadas visando a diminuição das emissões dos GEE. Incialmente, a empresa deve criar uma política voltada para as questões do aquecimento global e esta ser integrada as demais políticas da companhia. Em seguida a organização deve estabelecer objetivos e metas de reduções das emissões baseados no histórico de emissões, levantadas por meio dos inventários. Para garantir o atingimento dos objetivos de reduções é recomendado a criação de indicadores para o monitoramento do desempenho das ações de redução das emissões.

Aconselha-se a criação de um procedimento para a coleta de informações para a realização dos inventários, indicando quais informações são necessárias e o local (área) onde será coletada. Almeida (2002) afirma que a sustentabilidade ambiental empresarial deve ser encarada com uma postura proativa e preventiva, sendo tarefa da empresa o mapeamento dos riscos e oportunidades relacionados aos aspectos ambientais do negócio.

\section{CONCLUSÕES}

Há número crescente de organizações que estão adotando o mecanismo de inventário de GEE, contudo ainda é irrisório ao observa-se a totalidade de empresas existentes no país.

O estudo mostrou a importância de se conhecer as emissões de gases estufa nas companhias. O mapeamento das emissões de GEE da empresa estudada, realizado através ferramenta de cálculo do Programa Brasileiro GHG Protocol, possibilitou a discussão sobre criação de medidas de controle, monitoramento e redução desses gases dentro da organização.

Observou-se que as maiores emissões são de Escopo 1, aquelas controladas pela organização. Indicou-se medidas para redução com o foco nas fontes com maior percentual de contribuição total de emissões, como: o transporte de funcionários por automóveis próprios ou contratados, principalmente àqueles a base de óleo diesel; as emissões da fuga de SF6 e dos RAC; o consumo de energia elétrica e as advindas das viagens aéreas de funcionários. Tratou-se, ainda, de questões de nível institucional com a proposição de ações voltadas a construção de estrutura administrativa para gerenciar as fontes de emissões com propostas como a da criação de uma política voltada as questões climáticas.

Ao concluir-se o estudo espera-se que este contribua com a disseminação da cultura da elaboração de inventários de gases de efeito estufa pelas diversas organizações brasileiras, especialmente as empresas.

\section{REFERÊNCIAS}

ALMEIDA, F. O bom negócio da sustentabilidade. Rio de Janeiro: Nova Fronteira, 2002.

ANEEL. Matriz de Energia Elétrica. 2016. Agência

Nacional de Energia Elétrica. Disponível em: <http://www.aneel.gov.br/aplicacoes/capacidadebrasil/ OperacaoCapacidadeBrasil.cfm $>$ Acesso em: Set 2016. 
MAPEAMENTO DAS EMISSÕES DE GASES DE EFEITO ESTUFA EM UMA EMPRESA DO SETOR ENERGÉTICO

BARBIERI, J. C. Gestão ambiental empresarial: conceitos, modelos e instrumentos. 2. ed. São Paulo: Saraiva, 2007.

BRAGA, B.; HESPANHOL, I.; CONEJO, J. G. L.; MIERZWA, J. C.; BARROS, M.; SPENCER, M.; PORTO, M.; NUCCI, N.; JULIANO, N.; EIGER, S. Introdução à Engenharia Ambiental: o Desafio do Desenvolvimento Sustentável, $2^{a}$ edição. 2. ed. São Paulo: Pearson Prentice Hall, 2005.

BRASIL. Lei n.12.187, de 29 de dezembro de 2009. Institui a Política Nacional sobre Mudança do Clima - PNMC e dá outras providências. Brasilia: [s.n.], 2009. Disponível em: <http://www.planalto.gov. br/ccivil_03/_ato2007-2010/2009/lei/l12187.htm>. Acesso em: Abr 2018.

Decreto n. 7.390, de 9 de dezembro de 2010. Regulamenta os arts. 6o, 11 e 12 da Lei no 12.187, de 29 de dezembro de 2009, que institui a Política Nacional sobre Mudança do Clima - PNMC, e dá outras providências. Brasilia: [s.n.], 2010. Disponível em: <http://www.planalto.gov.br/ccivil_03/ _Ato2007-2010/2010/Decreto/D7390.htm>. Acesso em: Abr 2018.

BRASIL, G. H.; JUNIOR, P. A. D. S.; JUNIOR, J. A. D. C. Inventários corporativos de gases de efeito estufa: métodos e usos. Sistemas \& Gestão, v. 3, n. 1, p. 15-26, jan-abr 2008.

CALVACANTI, C. Desenvolvimento e natureza: estudos para uma sociedade sustentável. 5. ed. Recife: Cortez; Fundação Joaquim Nabuco, 2009.

CEARÁ. Lei n. 16.146, de 14 de dezembro de 2016. Institui a Politica Estadual sobre Mudanças Climáticas - PEMC. Fortaleza: [s.n.], 2016. Disponível em: <https://www2.al.ce.gov.br/legislativo/ legislacao5/leis2016/16146.htm>. Acesso em: Abr 2018.

CRUZ, F. A.; D’AVILA, S. L. Inventário de Emissões de Gases de Efeito Estufa da Universidade Tecnológica Federal do Paraná - Câmpus Curitiba. Curitiba, 2013.

FGV. Guia para a elaboração de inventários corporativos de emissões de gases do efeito estufa. São Paulo: Fundação Getúlio Vargas, 2009.

Programa Brasileiro GHG Protocol. 2016. Fundação Getúlio Vargas. Disponível em: <http://www.ghgprotocolbrasil.com.br>. Acesso em: Out 2016.
FIESP. Perguntas Frequentes sobre Mudança do

Clima. São Paulo, 2011.

GHG. Arquivos diversos. 2016. Greenhouse Gas Protoco. Disponível em: <http://www.ghgprotocol.org/ $>$ Acesso em: Out 2016.

GVCES. Propostas Empresariais de Políticas Públicas para uma Economia de Baixo Carbo No no Brasil: Energia, Transportes e Agropecuária. 1. ed. São Paulo: Vox Editora, 2010.

HOFFMAN, A. J. Getting ahead of the curve: Corporate strategies that address climate change. The University of Michigan: Pew Center on Global Climate Change Arlington, VA, 2006.

IPCC. Climate Change 2007: The Physical Science Basis - Summary for Policymakers. Geneva: IPCC Secretariat, 2007.

Climate change 2014-Impacts, adaptation and vulnerability: Regional aspects. Cambridge: Cambridge University Press, 2014. v. 1. Chapter 4. Disponível em: <http://www.ipcc.ch/report/ar5/wg2/> Acesso em: Abr 2016.

LÜCKEMEYER, A. Análise da matriz energética sob a visão sistêmica: programas energéticos governamentais e a redução de gases de efeito estufa. Dissertação (Mestrado em Tecnologia) Programa de Pós-Graduação em Tecnologia da Universidade Tecnológica Federal do Paraná, Curitiba, 2010. $170 \mathrm{f}$.

MACHADO, L. C. M. Metodologias para Estimativa de Emissões de Gases de Efeito Estufa na Produção de Óleo e Gás. Rio de Janeiro: UFRJ/ Escola Politécnica, 2013.

MAY, P.; LUSTOSA, M. C.; VINHA, V. Economia do meio ambiente. Rio de Janeiro: Elsevier Brasil, 2003.

MCTI. Arquivos diversos. 2016. Ministério da Ciência, Tecnologia e Inovação. Disponível em: <http://www.mct.gov.br/index.php/content/view/3881/ Mudancas_Climaticas.htm> Acesso em: Set 2016.

RICARDO, B.; CAMPANILI, M. Almanaque Brasil Socioambiental. São Paulo: ISA-Instituto Socioambiental, 2005.

SCHAEFFER, R.; SZKLO, A. S.; LUCENA, A. F. P. d.; SOUZA, R. R. d.; BORBA, B.; COSTA, I. V. L. d.; JR, A. P.; CUNHA, S. H. F. d. Mudanças climáticas e segurança energética no Brasil. Rio de Janeiro: COPPE/UFRJ, 2008. 
STERN, N. The Stern Review: The Economics of Climate Change. Londres: [s.n.], 2007. Disponível em: <http://mudancasclimaticas.cptec.inpe.br/ $\sim \mathrm{rmclima} / \mathrm{pdfs} /$ destaques/sternreview_report_ complete.pdf> Acesso em: Set 2016.

UNFCCC. Kyoto Protocol To The United Nations Framework Convention On Climate Change. 1998. United Nations Framework Convention on Climate Change. Disponível em: $<$ http://unfccc.int/resource/docs/convkp/kpeng.pdf> Acesso em: Set 2016.

WRI. The Greenhouse Gas Protocol: A corporate accounting and reporting standard. 2004. World Resources Institute \& WBCSD - World Business Council for Sustainable Development. Washington. Disponível em: $<$ http://pdf.wri.org/ghg_protocol_2004.pdf $>$, Acesso em: Out 2016. 